\title{
Modeling groundwater flow and salinity evolution near TSF Żelazny Most. Part II - chloride transport
}

\author{
Waldemar Świdziński \\ Institute of Hydro-Engineering, Polish Academy of Sciences, IBW PAN, Gdańsk, Poland
}

\section{INTRODUCTION}

In Part I of this set of two papers a 3D hydrogeological numerical model (Figure 1) simulating the groundwater flow regime near the huge Tailings Storage Facility Żelazny Most, Poland was described and discussed. TSF Żelazny Most stores post-flotation tailings which are a by-product of copper mining and its extraction. The tailings are transported and discharged into the facility as a slurry containing highly saline waters which can infiltrate into groundwater strongly impacting the water environment near the TSF. Essential part of these waters is intercepted by comprehensively developed drainage system, however some small portion still passes by the drainage and enters groundwater and finally the neighboring surface watercourses. The aim of the model was to have efficient tool to simulate the groundwater flow pattern near the TSF and the transport of saline waters seeping from the facility. The results presented in Part I showed that after careful calibration and validation the model acceptably well reproduces real groundwater flow conditions within the modelled area. Next, based on the 3D model the migration of saline waters was simulated and confronted with the in situ measurements of the range and concentration of chlorides downstream the facility. The final step was the prediction of the change of groundwater flow regime due to increasing water level in TSF at higher elevations of the dams and stored tailings, and the associated changes of contaminated zones with the course of the facility development. In Part II the simulation of chloride transport near TSF by 3D model is described and the predicted development of salinity zones is presented.

\section{MIGRATION OF SALINE WATERS WITHIN THE MASS OF TAILINGS}

The seepage process from the pond through the mass of tailings and dam is generally determined by two factors: the water head and the permeability properties of tailings and subsoil layers. The conditions for infiltration of saline waters in the mass of tailings are dependent on its gradation which is the result of segregation and sedimentation during the spigotting process. Coarse fractions of relatively high permeability are deposited near the embankments whereas the finest fractions are deposited near the pond and, due to sedimentation process, onto its bed. Thus the infiltration of saline water throughout the tailings cannot be avoided, particularly in the close distance from the embankments. Essential portion of water infiltrates into the tailings mass via beaches of the facility during discharging of a slurry. The closer distance to the embankments the more intensive infiltration occurs. The spigotting is carried out periodically section by section which means that for a given section it effectively lasts $11 \%$ of the year, only. In the periods between spigotting the process of draining and drying takes place. However, huge reservoir of water stored in tailing mass (voids) causes that the drainage process is strongly delayed and lasts much longer than breaks between consequent discharges. It induces overlapping the effects of following discharges and equalization of the rate of water infiltrating into the subsoil. Therefore, continuous infiltration of saline waters has been assumed in the model. 


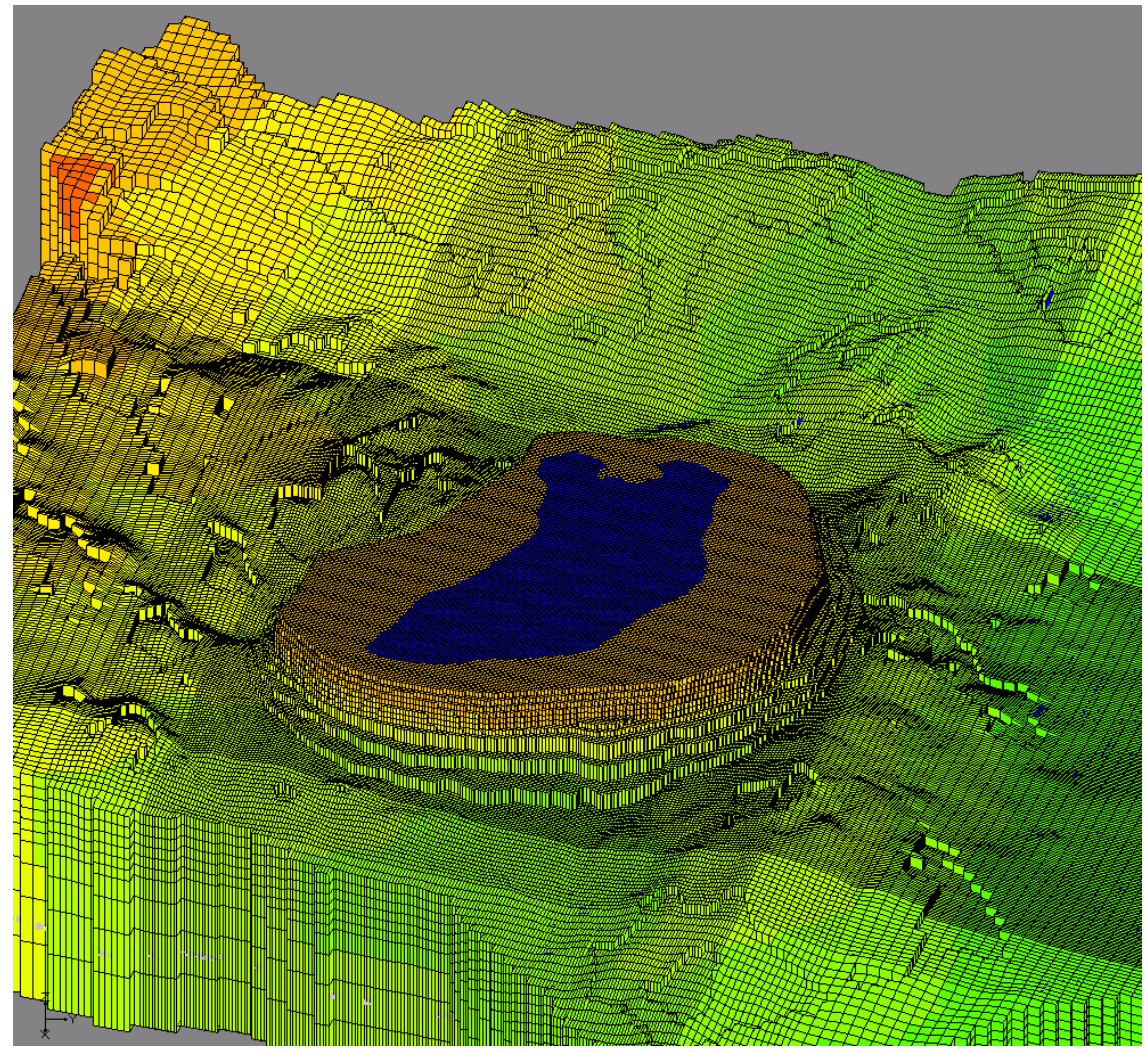

Figure 1. 3D hydrogeological model of TSF Żelazny Most area (Świdziński et al. 2012).

Segregation of tailings during discharging of a slurry as well as controlled discharge of finest material directly into the center of the facility cause large variety of hydraulic permeability of tailings both in vertical and horizontal directions and complex flow conditions within the tailings mass. In situ investigations of the permeability as a function of a distance from the East and West dam embankments, carried out in the past, have clearly revealed that near the pond values of coefficient of permeability are close to those corresponding to impermeable soils $\left(10^{-9} \mathrm{~m} / \mathrm{s}\right)$ whereas near the embankments these values represent fully permeable material $\left(10^{-4} \mathrm{~m} / \mathrm{s}\right)$. Moreover, the mass of tailings is a strongly anisotropic medium due to numerous laminations of semipervious layers which may partly result from the process of beach stabilization by asphalt emulsion against dusting, however correct determination of the anisotropy degree of tailings stored in the depository is very difficult. Based on infiltrometric tests the value of anisotropy can be assumed as $\mathrm{K}_{\mathrm{H}} / \mathrm{K}_{\mathrm{V}} \approx$ $2 \div 3$. However, the interpretation of piezometric heads observed in tailings shows that this ratio can be much higher $-\mathrm{K}_{\mathrm{H}} / \mathrm{K}_{\mathrm{V}} \geq 10 \div 15$.

The 3D model has been first calibrated for the conditions occurring at TSF at the end of 2005 and re-calibrated for 2012 implementing new information regarding the hydrogeological conditions of the subsoil. Next the model has been used to predict the impact of TSF Żelazny Most on surface and groundwaters for higher elevations related to planned lifetime of the facility. Due to some limitations, in this paper the prediction of the impact in years 2005-2012 will be presented, only.

The results of modelling of groundwater flow regime within the facility and downstream have revealed that the waters infiltrate mainly through the area of beaches during the discharging of a slurry in the proportion of $99 \%$ of all waters infiltrating from the facility whereas percolation from the pond amounts 1\%, only (Świdziński, 2018). Such result can be justified taking into account drastic reduction of tailings permeability with the distance from the surrounding dams towards the pond. 


\section{MODELLING THE MIGRATION OF SALINE WATERS NEAR THE FACILITY}

In order to model the migration of saline waters in groundwater MT3D (Modular Transport 3 Dimensional) software was used and to solve the advection-diffusion equation third order TVD scheme (ultimate) or MMOC (Modified Method Of Characteristics) were applied, both being an integral part of GMS package. The conservative chlorides were selected as a the modelled substance, since they do not undergo sorption process, nor react with other chemical compounds. Moreover, the chlorides, besides sulphates, are the main indicator of polluted groundwater near the facility, and thus enable a reliable assessment of changes occurring in aquatic environment caused by the facility operation. The waters discharged to the facility with tailings come from dewatering of the copper mines. They are reach in salts, the concentration of which increases with the course of exploration of new mining fields. In Figure 2 the changes of average annual values of chlorides concentration in water discharged with tailings into TSF Żelazny Most starting from 1996 till 2012 are shown.

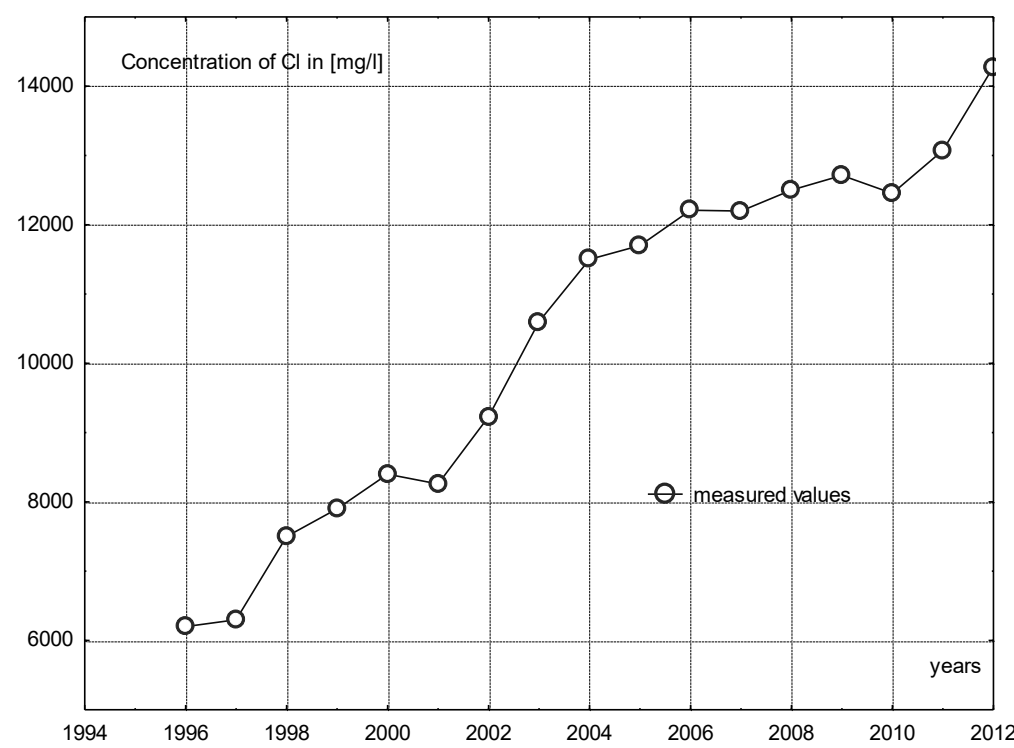

Figure 2. Mean annual concentration of chlorides in waters stored in the TSF Żelazny Most.

For the model calibrated at the end of 2005 the value of chlorides concentration in mine waters discharged into the facility was $11000 \mathrm{mg} \mathrm{Cl} / \mathrm{dm}^{3}$ and it increased at the end of 2012 up to $14280 \mathrm{mg} \mathrm{Cl} / \mathrm{dm}^{3}$. It was assumed that excess state over hydrochemical background would be modeled, only. Within the model domain woodlands and agricultural as well as meadow areas dominate, for which the average natural concentration of chlorides is $40 \mathrm{mg} \mathrm{Cl} / \mathrm{dm}^{3}$. Therefore, for the sake of simplicity as the ultimate value for groundwater pollution by chlorides $210 \mathrm{mgCl} / \mathrm{dm}^{3}$ was assumed so as the total chlorides concentration would not exceed the ultimate value assigned to the III class clean water $\left(250 \mathrm{mg} \mathrm{Cl} / \mathrm{dm}^{3}\right)$, the last class corresponding to good quality water according to the recent Polish regulations. Consequently, the initial condition in the form of given concentration of salts was applied only for the areas polluted by saline waters from the facility identified by the in situ measurements. Such measurements are being carried out annually in the frame of operational monitoring. The distribution of concentration of salts in the groundwater downstream the facility, introduced to the model as initial condition, corresponded to that observed in 2005 , 
the year the model was originally calibrated and validated. For the rest of areas the concentration of chlorides was assumed to be 0 . In turn, in order to model the intrusion of saline waters during the spigotting the slurry over the beaches and from the pond first-type boundary condition was assumed. The condition relies on providing the value of chlorides concentration for specified grid blocks. As it is shown in Figure 2 the concentration of chlorides increases with time, thus such change had also to be incorporated into the prognostic calculations for 2012. The dispersion process was modelled using two hydrodynamic dispersion constants i.e. longitudinal $\left(\alpha_{\mathrm{L}}\right)$ and transverse $\left(\alpha_{\mathrm{T}}\right)$. For the analysed case $20 \mathrm{~m}$ and $6 \mathrm{~m}$ for longitudinal and transverse dispersion constants were assumed, respectively. Moreover, the effective porosity of the foundation soils varied depending on their permeability, while for the tailings a constant value was assumed. Taking into account that the rate of facility development is relatively slow (increase of water level in the pond $1.5 \mathrm{~m} /$ year) as well as that the in situ observations show small fluctuations of groundwater level near the TSF, steady-state flow conditions have been incorporated. Little change of groundwater regime near the TSF is mostly caused by the work of drainage system overtaking the essential portions of water infiltrating into the subsoil in the near downstream whereas far downstream groundwater level is mostly impacted by precipitation. Despite the stationarity of flow process assumed, in long-term predictions quasi non-steadystate approach was applied by execution of calculations for higher elevations of the dams in several time steps. The calculation stages of groundwater flow regime were coupled with the simulation of chloride transport in groundwater. The latter was modelled as fully non-steadystate process based on the stationary hydrodynamic field being the solution for a given time step (assumed to be one year starting from 2005). The elevations of the water in the pond for consequent years were introduced into the model based on the real measurements at the end of the year. The initial condition for calibration year (2005) was the distribution of the concentration of chlorides in the groundwater downstream the facility based on in situ measurements. In turn, the initial condition for the concentration of chlorides in subsequent years was the distribution of this concentration downstream the facility being the result of numerical calculations for previous year as well as average concentration of chlorides in the pond based on the in situ observations.

Table 1. Predicted budget of groundwater near TSF Żelazny Most .

\begin{tabular}{|c|c|c|c|c|}
\hline & $\begin{array}{c}\text { Inflow } \\
\mathrm{m}^{3} / \mathrm{s}\end{array}$ & $\begin{array}{c}\text { Inflow } \\
\mathrm{m}^{3} / \mathrm{d}\end{array}$ & $\begin{array}{c}\text { Outflow } \\
\mathrm{m}^{3} / \mathrm{s}\end{array}$ & $\begin{array}{c}\text { Outflow } \\
\mathrm{m}^{3} / \mathrm{d}\end{array}$ \\
\hline Infiltration from the pond & 0.00248 & 214 & - & - \\
\hline Infiltration through the beaches & 0.37910 & 32754 & - & - \\
\hline Precipitation through the dams & 0.01650 & 1426 & - & - \\
\hline Discharge of drainage wells & - & - & 0.14474 & 12506 \\
\hline Discharge of horizontal drainage system & - & - & 0.23393 & 20212 \\
\hline Total & 0.39808 & 34394 & 0.37867 & 32718 \\
\hline Difference between inflows and outflows & & & 0.01940 & 1676 \\
\hline
\end{tabular}

\section{THE RESULTS OF NUMERICAL SIMULATIONS}

The groundwater budget for the area of the facility and its closest vicinity (including the location of drainage wells) calculated by the numerical model for the end of 2012 is presented in Table 1. According to the results given in Table 1, at the end of 2012 the amount of saline waters not captured by the drainage system flowing out of the facility 
downstream was $1676 \mathrm{~m}^{3} /$ day and it was lower comparing to $2005\left(2078 \mathrm{~m}^{3} /\right.$ day, (Świdziński et al. 2011). It can be also seen that the amount of waters seeping downstream is equivalent to approximately $5 \%$ of total amount of waters infiltrating through the mass of tailings into the subsoil whereas $95 \%$ of it is captured by drainage system. Modelled range of groundwater with concentration of chlorides higher than limit level $\left(>250 \mathrm{mg} \mathrm{Cl} / \mathrm{dm}^{3}-\right.$ solid line) together with the pollution zones based on in situ measurements (filled areas) for 2012 is shown in Figure 3.

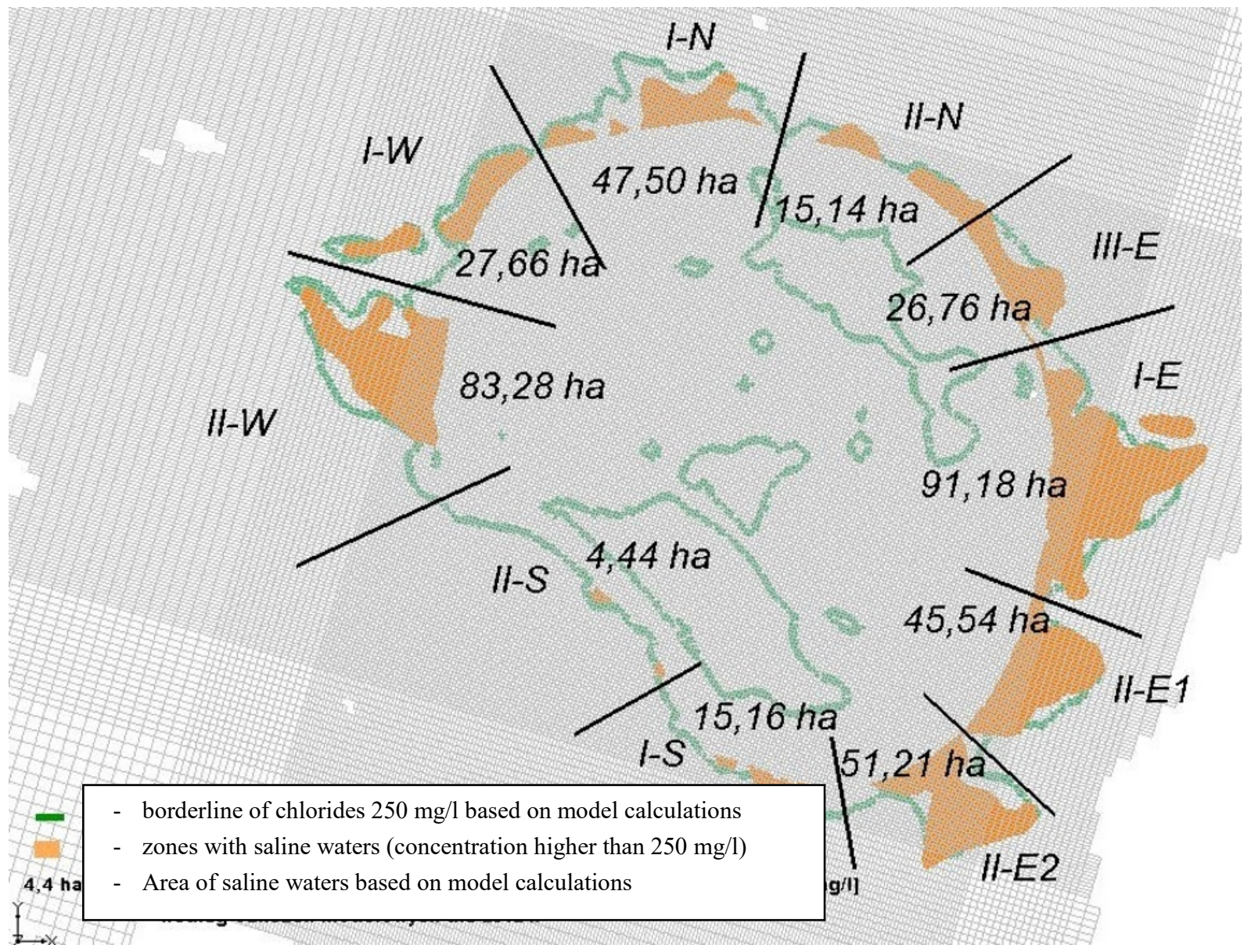
Figure 3. Measured and calculated ranges of polluted groundwater downstream TSF
Żelazny Most at the end of 2012.

Simulated total polluted area is approximately 92 ha larger than resulting from in situ measurements $(\sim 316 \mathrm{ha})$, however both the maximum ranges as well as the shape of polluted zones designated by the $250 \mathrm{Clmg} / \mathrm{dm}^{3}$ contour, are similar. There are some regions where modelling results show the presence of chlorides higher than the limit value which is not confirmed by the results of operational monitoring e.g. larger range of saline waters in zone I-N downstream north dam as well as opposite situations e.g. zone I-E in the central part of east dam. There are also some separated regions where field measurements do not show higher concentration of chlorides whereas they are simulated by the numerical model (e.g. the polluted ,island” in zone I-E). Best quantitative agreement with regard to the polluted area has been achieved for eastern part for which the difference between measured and simulated results was around $9 \%$ what proves good calibration of the model for this particular region. Somewhat worse agreement was obtained for the rest of the dams. In general, the numerical results overestimate the in situ observations whereas quite good 
reproduction of the shapes of polluted zones is observed. The largest difference with regard to the polluted area is for northern part $(100 \%)$ and $50 \%$ for western area downstream the facility, however it should be noted that the total contribution of these areas is lower than the eastern part.

\section{DISCUSSION AND CONCLUSIONS}

In the set of two papers a 3D numerical model which simulates groundwater flow and its chemical changes caused by the largest Tailings Storage Facility Żelazny Most, Poland has been presented. The model serves mainly for prediction of the potential future changes of groundwater flow regime and the extent of contamination by salinity downstream the facility in the course of its further development. The results of predictive simulations for the period 2005-2012, confronted with in situ observations, have proved that the model quite well reproduces the shape, range and area of polluted zones. Long-term in situ measurements of the salinity of groundwater, carried out every year in hundreds of the observation points near the TSF, show that the polluted areas do not change too much. It was confirmed by predictive simulations for the whole planned lifetime of the facility (results not presented here). The results of numerical calculations have shown that the situation should not essentially change in future and a decrease of the amount of saline waters flowing out of the facility can be expected. It means that the hydraulic barrier created by drainage wells installed around the facility efficiently prevents the outflow of saline waters downstream the facility.

\section{REFERENCES}

Świdziński W. 2018 Modelling of saline waters transport in groundwater near Tailing Storage Facility (TSF). Part I - hydrodynamics of groundwater. SWIM proceedings (to be supplemented later on).

Świdziński W., Maciejewski St., Walter A. and Franz M. 2011. Prediction of the Żelazny Most facility impact on ground and surface waters during its operation to the elevation of $195 \mathrm{~m}$ a.s.l. and after its closure. Report for KGHM POLSKA MIEDŹ S.A.

Świdziński W., Maciejewski St., Walter A. 2014. Integrated assessment of the impact of the „Żelazny Most” facility on ground and surface waters till 2012 together with updated protection plan. Report for KGHM POLSKA MIEDŹ S.A.

Contact Information: Waldemar Świdziński, Institute of Hydro-Engineering PAS, Department of Geomechanics, Kościerska 7, 80-328 Gdańsk, Poland, Phone: +48585222945, Fax: +48585524211, Email:waldek@ibwpan.gda.pl. 